Marquette University

e-Publications@Marquette

$1-1-2016$

Exploring Supply Chain Relationships and Information Exchange in UK Grocery Supply Chains: Some Preliminary Findings

Mark Barratt

Marquette University, mark.barratt@marquette.edu

Accepted version. "Exploring Supply Chain Relationships and Information Exchange in UK Grocery Supply Chains: Some Preliminary Findings," in Developments in Logistics and Supply Chain Management: Past, Present and Future. Eds. Kulwant S. Pawar, Helen Rogers, Andrew Potter and Mohamed Naim. Basingstoke: Palgrave Macmillan, 2016: 181-188. (c) Palgrave Macmillan 2016. Reproduced with permission of Palgrave Macmillan. This extract is taken from the author's original manuscript and has not been edited. The definitive, published, version of record is available here: Publisher link. 


\title{
Exploring Supply Chain Relationships and Information Exchange in UK Grocery Supply Chains: Some Preliminary Findings
}

\author{
Mark Barratt \\ Management, Marquette University \\ Milwaukee, WI
}

\section{Literature review}

Despite the concept of supply chain management having existed since the early 1980s (Oliver and Webber, 1982; Houlihan, 1984, 1985), there is still significant confusion as to the meaning of the concept and particularly as to how to implement it (Kearney, 1994; Neuman and Samuels, 1996). Such confusion is further enhanced by the multitude of terminology and definitions (New, 1996; McGuffog, 1997) arising from the academic and practitioner literature.

One aspect of the SCM concept is clear, in order to coordinate the supply chain as a whole, cooperative relationships based upon 
mutual dependency (Atkin, 1993) must be developed between the organisations in the chain. Such relationships must replace the more traditional adversarial relationships which have fostered a "silo" or "trench warfare" mentality resulting in extremely inefficient and ineffective supply chains (McGuffog, 1997). There is clear evidence that some organisations have recognised this and are attempting to implement such an approach within the management of their supply chains (Kearney, 1994), however, there would appear to be a bias towards the formation of relationships with customers at the expense of relationships with suppliers (Kearney, 1994). It is not clear as to the reasons for this apparent bias.

Limited empirical work has been undertaken in modelling and studying supply chain relationships. Most research carried out in this area has focused on one relationship or a single level of the supply chain, such as buyer/seller, shipper/carrier, and so on (Ellram, 1991; Harland, 1996). Such research appears to ignore the systemic view of supply chain philosophy; moreover, the traditional "pipeline" view of the supply chain needs to be replaced with that of the "inter-business network" (Harland, 1996; Juga, 1996). Many of the definitions of SCM lend themselves to the representation of the supply chain as either a network (Christopher, 1992; Juga, 1996) or that of the external supply chain (Houlihan, 1985; Stevens, 1989; Davis, 1993). However, much of the existing research in to supply chains is in the form of internal supply chains (Oliver and Webber, 1982) or dyadic relationships (Cooper and Ellram 1993). Thus, there is a distinct need for research into supply chains as networks of relationships between organisations. This view is supported by Harland (1996) who suggests that "as there is a move towards network relationships, the need for research in external supply chains and networks will increase".

It is also clear from the literature that organisations must share demand and cost information if competitive advantages are to be achieved (Kearney, 1994; Christopher, 1997). If organisations continue with the practice of charging for forecast or demand data (Kearney, 1994), then the ideal of cooperative relationships is not likely to be achieved. It has also been suggested that information sharing is not open and extensive but restricted and selective (Ogbonna and Wilkinson, 1996). There is a distinction between own- 
label suppliers, whose relationships with retailers in many cases appear to be increasingly close, and branded manufacturers, with whom the relationship remains selectively distant (Ogbonna and Wilkinson, 1996). Christopher (1997) suggests that the way forward is a re-orientation of the supply chain towards cooperation through shared information.

From the literature review, a number of research themes emerged, which were to form the focus of the research. The themes identified were as detailed in Figure 5.3.1. For the purposes of this paper only, findings pertaining to the supply chain relationships and information in the supply chain themes will be presented. Supply chain relationships are considered by the literature as critical to supply chain integration. Many authors (e.g., Kearney, 1994; Christopher, 1997) suggest that information exchange is key to obtaining competitive advantage.

\section{Research methodology}

In a subject area that has traditionally borrowed theoretical insight from other disciplines rather than developing its own theories, the research undertaken here is part of a wider exploratory study, whose aim is to develop theoretical propositions concerning the implementation of cooperative supply chain relationships based upon information exchange. The chosen research methodology for this paper is that of the case study. A number of authors have highlighted the growing interest in the management discipline in the use of case study based research (Eisenhardt, 1989; Ellram, 1996). Ellram (1996) goes on to suggest that empirical research can include either quantitative analysis, qualitative analysis or a mixture of both. She also suggests that qualitative results are frequently expressed verbally, often to create an understanding of relationships or complex interactions. Ellram (1996) suggests that case studies focus on holistic situations (i.e., a supply chain) in real life settings and tend to have set boundaries of interest, such as an organisation, a particular industry or particular type of operation. Yin (1981) suggests that a case study method is often chosen because the researcher wants to know how the context of the phenomenon of interest affects the outcomes. 
A number of authors (Hogarth-Scott and Parkinson, 1993; Ellram, 1996; Juga, 1996) support the use of the case study method in logistics and supply chain management research. Going beyond Yin's (1981) initial criteria, the case study method is deemed to be particularly appropriate in a supply chain management context for the following reasons: Firstly, the difficulty in distinguishing between a phenomena (a cooperative supply chain relationship) and its context (the UK retail grocery sector) (Yin, 1981). It is argued by the author that the sector is made up of a myriad of relationships between organisations, that when considered collectively, form the UK retail grocery sector. Secondly, the immaturity of the field of logistics and supply management.

\section{Pilot study research findings}

The pilot was undertaken to compare the findings of the literature review, as summarised above, with the current thoughts and views of a cross section of practitioners from various roles and positions in the UK retail grocery sector. The pilot was also used to raise further issues for consideration in the subsequent main part of the author's study. As the context of the research is supply chains within the UK grocery sector, it was decided by the author to approach organisations with varying roles and positions in such supply chains. Interviews were undertaken with the following types of organisations: four retailers; five grocery manufacturers; two raw material suppliers; two logistics providers; one packaging supplier; one farmer, one IT service provider and five supply chain consultants. The preliminary findings from the pilot study follow.

\section{Status of relationships}

There are signs that while many relationships are still adversarial in their nature, there is a degree of migration towards more cooperative types of relationships. A number of the manufacturers interviewed are now reporting more cooperative relationships with retailing counterparts. 
NOT THE PUBLISHED VERSION; this is the author's final, peer-reviewed manuscript. The published version may be accessed by following the link in the citation at the bottom of the page.

\section{Relationship objectives}

Objectives appear to be mainly financial, but are also focused upon improving service levels and developing a greater understanding of activities in the supply chain.

Relationship benefits include: growing the business, total supply chain cost reduction, improved knowledge of how the supply chain operates, improved service levels, reduction of inventory, improved standardisation of processes, systems, etc. and, most importantly, improved communication.

Types and basis of relationships are mutual, strategic, broader (wider relationship interface), positive, communicative, longer term, process alignment, information based. Relationships are based upon mutuality, trust, understanding, focused (by category), value adding and empowering.

Relationship problems include severe lack of understanding of needs (supplier, customer and consumer), technical (lack of standardised integrated systems), culture, lack of shared objectives, control (poor understanding of supply chain specific performance measures).

Cooperation and key success factors are sharing (exchange of personnel), teams (multi-disciplinary), recognition (that relationships can take on many forms), organisational (inter-board participation). Understanding common process requirements, mutuality, strategic (in terms of longer term), commonality, financial benefit, consumer focused, innovative, open, senior management.

Several key areas relating to information in supply were identified, and these are summarised as follows:

\section{The role of information}

Accurate timely information (as opposed to data) can remove significant inventory costs from the supply chain. Critical to the 
NOT THE PUBLISHED VERSION; this is the author's final, peer-reviewed manuscript. The published version may be accessed by following the link in the citation at the bottom of the page.

functioning of the integrated supply chain, information also enables enhanced decisionmaking providing greater certainty.

\section{Why share information?}

Sharing information offers increased visibility across the supply chain and enables participating organisations to synchronise their activities and improve their responsiveness.

\section{Benefits of information exchange}

Exchanging information across the supply chain offers benefits that include, informed decision-making resulting from improved visibility, automation of order processing, inventory minimisation together with improved responsiveness (in terms of service and promotions) and on-shelf product availability.

\section{What information to exchange}

Demand information (consolidated at regional distribution centre level) on as close to a real time basis, product information including inventory levels, promotional information, forecast information, new product information.

\section{How information is exchanged}

Information should be shared electronically, via Internet based intranet/extranet systems. There are still signs that information is communicated via faxes and telephones due to the lack of system integration. Retailers and manufacturers are already adopting this medium of information exchange.

\section{Barriers to information exchange}

Many barriers to information exchange exist. These include: information standards (one manufacturer was faced with dealing with three separate Internet based systems used by retailer customers), organizational (information is still regarded as a source of power) and 
individual mindsets (there is a lack of people with the ability to understand the implications usage's of information exchange), commercial sensitivity, cost (although the Internet is providing a cheaper alternative), ability to collect, share and process information and understanding of the role of information and the need to exchange such information across the supply chain.

\section{Conclusions}

A number of organisations, including retailers and manufacturers, recognise the need to develop cooperative relationships throughout their supply chains. However, these organisations accept that the development of such relationships means a significant upheaval within their organisations. Such upheaval is due to the need to develop an organizational supply chain view, which is contrary the traditional working practices of most employees in organisations. All of the retailers interviewed are developing relationships, albeit with a limited number of suppliers, based upon the sharing of information (via the Internet), shared resources, mutual commitment and an awareness that a longer term view of supply chain management must be adopted if it is to be successful.

There are two distinct views regarding the role of information. In the retail and manufacturing organisations interviewed, information regarding consumer demand is seen as vital to reducing total supply chain costs. In organisations much further removed from the consumer, the role of information is not so clearly understood. This may be due to the fact that the concept of supply chain management is not so clearly understood or appreciated. An ongoing mistrust of large retailers may also be grounds for the lack of willingness to enter relationships with such organisations or to exchange information, which may in fact be beneficial to both organisations.

The next phase of the author's study is a case study of an entire supply chain, beginning with a retailer and including manufacturer, raw material suppliers, packaging suppliers, logistics providers and IT service providers. All interfaces between the organisations (both internally and externally) will be examined, together with an 
NOT THE PUBLISHED VERSION; this is the author's final, peer-reviewed manuscript. The published version may be accessed by following the link in the citation at the bottom of the page.

examination of the impact of information exchange upon the supply chain as a whole.

\section{References}

Atkin, R. (1993) "Supply chain management: to maximise resource usage \& maximise service", BPICS Control, June/July, 25-28.

Christopher, M. G. (1992) Logistics and Supply Chain Management: Strategies for Reducing Costs and Improving Services Pitman, London.

Christopher, M. (1997) Marketing Logistics, Butterworth-Heinemann, Oxford.

Cooper, M. C. and Ellram, L. M. (1993) "Characteristics of supply chain management and the implications for purchasing and logistics strategy", International Journal of Logistics Management, 4(2), 13-24.

Davis, T. (1993) "Effective supply chain management", Sloan Management Review, Summer 1993, 35-46.

Eisenhardt, K. M. (1989) "Building theories from case study research", Academy of Management Review, 14(4), 532-550.

Ellram, L. M. (1991) "Supply chain management: the industrial organization perspective", International Journal of Physical Distribution and Logistics Management, 21(1), 13-22.

Ellram, L. M. (1996) "The use of the case study method in logistics research", Journal of Business Logistics, 17(2), 93-138.

Harland, C. M. (1996) "Supply chain management: relationships, chains and networks", British Journal of Management, 7(March 1996), 63-80.

Hogarth-Scott, S. and Parkinson, S. (1993) "Retailer-supplier relationships in the food channel: a supplier perspective", International Journal of Retail and Distribution Management, 21(8), 11-18.

Houlihan, J. B. (1984) "Supply chain management", Proceedings of the $19^{\text {th }}$ International Technical Conference of the British Production and Inventory Control Society, 101-110.

Houlihan, J. B. (1985) "International supply chain management", International Journal of Physical Distribution \& Materials Management, $15(1), 22-38$

Juga, J. (1996) "Organising for network synergy in logistics", International Journal of Physical Distribution and Logistics Management, 26(2), 5167.

Kearney, A. T. (1994) Partnership or Power Play?, Consultancy Report in conjunction with UMIST School of Management.

McGuffog, T. (1997) "The Obligation to keep value chain management simple and standard", Supply Chain Management, 2(4), 124-133.

Neuman, J. and Samuels, C. (1996) "Supply chain integration: vision or reality!", Supply Chain Management, 1(2), 7-10. 
New, S. J. (1996) "A framework for analysing supply chain improvement", International Journal of Operations and Production Management, $16(4), 19-34$.

Ogbonna, E. and Wilkinson, B. (1996) "Information technology and power in the UK grocery distribution chain", Journal of General Management, 22(2), 20-35.

Oliver, R. K and Webber, M. D. (1982) "Supply chain management: logistics catches up with strategy," in Christopher, M. (ed.), Logistics: The Strategic Issues, Chapman and Hall, London.

Stevens, G. C. (1989), "Integrating the supply chain", International Journal of Physical Distribution and Materials Management, 8(8), 3-8.

Yin, R. K. (1981) "The case study crisis: some answers", Administrative Science Quarterly, 26, 58-65.

Figure 5.3.1 Research themes

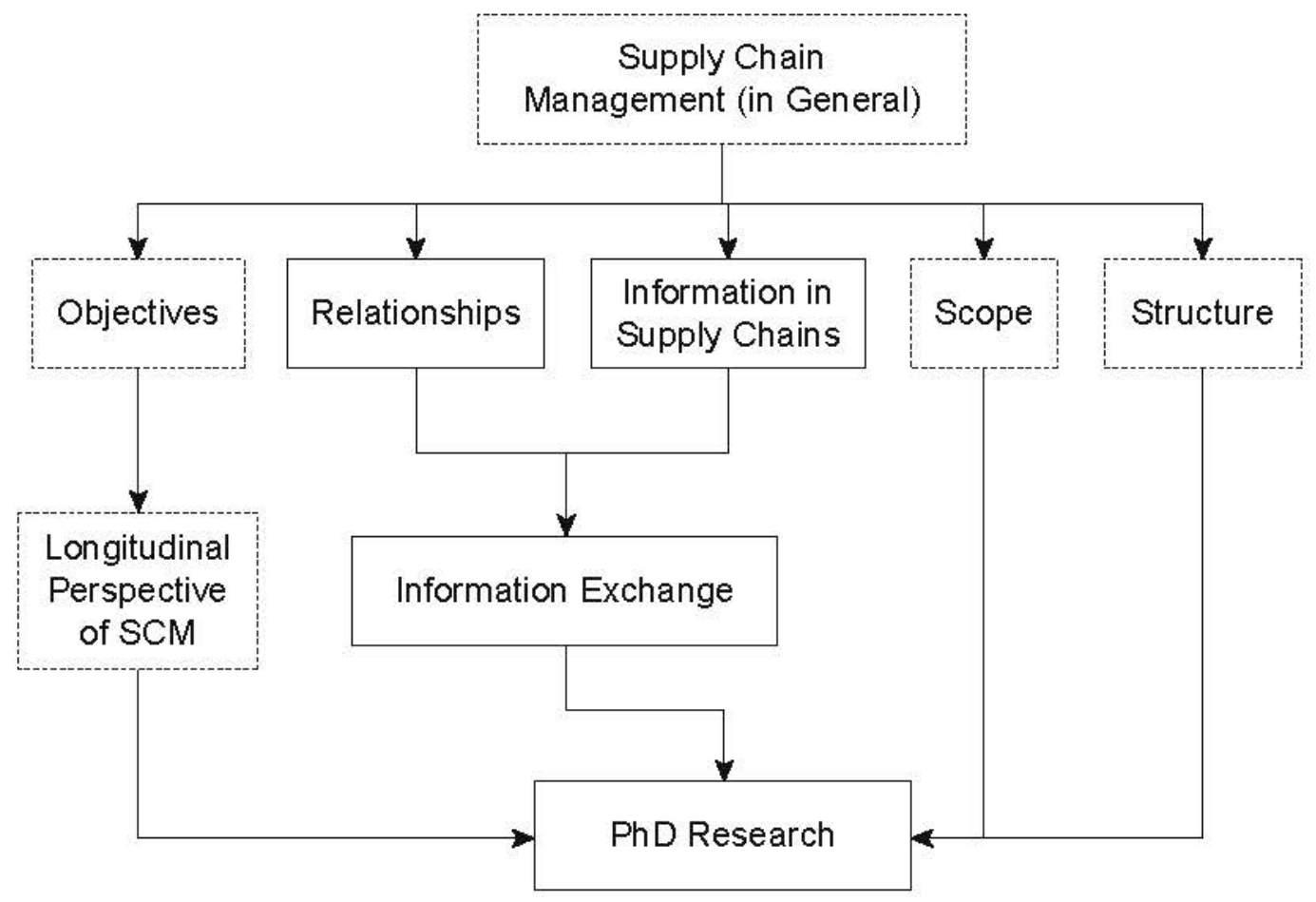

Developments in Logistics and Supply Chain Management: Past, Present and Future, (2016): pg. 181-188. Publisher link. This article is (C) Palgrave-Macmillan Publishing and permission has been granted for this version to appear in ePublications@Marquette. Palgrave-Macmillan Publishing does not grant permission for this article to be further copied/distributed or hosted elsewhere without the express permission from Palgrave-Macmillan Publishing. 